\title{
Test problems composition methodology of different degrees of difficulties for the "Computer graphics" discipline
}

\author{
Umida Nasritdinova* \\ Tashkent institute of irrigation and agricultural mechanization engineers, Tashkent, Uzbekistan
}

\begin{abstract}
Improving the effectiveness of education in the teaching of computer graphics is the organization of the educational process using new information and communication technologies, as well as quality control of the learning modules. With this in mind, the article provides a theoretical analysis of the methodology of compiling test questions from computer graphics and some related graphic disciplines. The relationship of factor theory to the graphical sciences has been identified. As a result, the threelevel test task system structure based on specific formulas and their factors has been studied so far. Also, the system of assessment of students in four categories was tested using a general automated software tool for questionnaires and test control. Based on the results, mathematical statistical analysis was performed, and the range of variation of the four categories was shown.
\end{abstract}

\section{Introduction}

Nowadays, the development of the graphic education system involves the use of convenient means and methods of comprehensive control of the level of knowledge and skills acquired by young specialists. These funds today consist of widespread oral, written and test types of control, and all of them are the main guarantor of strengthening the knowledge acquired by students.

For example, when monitoring students' knowledge in the disciplines "Descriptive geometry and engineering graphics", "Computer graphics", along with oral and written types of knowledge control, testing is also used. As we know, nowadays, this type of control is more often used on the basis of computer technology, and this gives more effective results, but to further improve the quality of education, develop students' desire to gain knowledge, identify the most capable students in the field of graphic education and step-by-step development of their knowledge and skills is an urgent problem to create a methodology for compiling test items of varying degrees of complexity and their development [1].

Modern test theory is formed on the basis of the interaction of pedagogy, psychology, logic, mathematical statistics, information theory, cybernetics and other sciences. A highquality pedagogical test allows you to accurately, correctly and objectively assess the level of knowledge of pupils and students. More than a century of experience in many countries shows that professionally designed tests in the education system are necessary as formulas in physics. Pedagogical tests, having positive opportunities, allow improving the quality of knowledge in all areas of education. Therefore, to have certain knowledge in the field of

*Corresponding author: umiasp@mail.ru 
tests is one of the main tasks of every teacher and employee of the educational administration [2].

The issues of pedagogical measurement and assessment are well studied in the works of V.S. Avanesov, G. Alimov, V.I. Vasiliev, F.A. Dzhumabayeva, T.N. Zaichikova, F. Mambetov, V.B. Chelishkova, A. Morev, Gu Rush, H. Suena, G. F. Kuder, M. V. Richardson, V.M. Sviridenko, L. Yanoshi, Ch. Shokirova and others and are used in practice.

Pedagogical tests are an integral part of many innovations in the education system, including the concept of pedagogical technology and the technology of complete assimilation. These concepts are approved by UNESCO and are widely used in many states. If the test is correctly drawn up, it allows you to objectively assess the student's knowledge since this assessment will not be associated with the teacher's personality. Correctly solved test items are assessed based on certain criteria. Therefore, tests are called accurate and objective means of pedagogical assessment of knowledge. But only a test drawn up at a high professional level can give such results. The reliability of a test is reflected in the accuracy of the measure of knowledge identified by that test. Determining the reliability of a test, first of all, aims at revealing how much you can trust the results of this test $[3,4]$.

In developing a methodology for compiling tests of varying degrees of complexity in the discipline "Computer Graphics", based on the goals and content, objectives of the discipline, we found it necessary to look at the subjects that the student should master, as the main factors and the number and degree of complexity of these particular factors observed among students, are related to the degree of test difficulty, which is what we took as a basis.

The development of modern computer technologies opens the door to wide opportunities in the field of education and creates the necessary conditions for the perfect mastery of future specialists in their speciality. Information technologies are developing so rapidly that pedagogical research does not have time to analyze new methods, forms and means of teaching $[5,6]$.

That is why, in all higher educational institutions in the educational activities of teachers, computer technologies are used as a modern methodology. Modern multimedia computer programs and telecommunication technologies open the way for students to sources of information, electronic hypertext textbooks, educational sites, to the system of distance education, etc. [7-9].

The intellectual ability in students under the influence of certain high requirements is much more developed than in schoolchildren $[10,11]$. Therefore, the student must have a well-developed body of knowledge such as the ability to determine the goals of knowledge abilities, analyze educational tasks, and choose ways to solve a problem. It is known that not all students have this ability. Special studies carried out by psychologists have determined the diversity of students' intellectual activity and, especially, highlighting intellectual ability among them. For the development of students' intellectual ability, we need to achieve the effectiveness of educational activities.

The creation and application of automated software for determining students' interest, ability, and knowledge in the educational process provides for identifying the way the teacher organizes educational activities. Because, since the degree of mastering by students of the subject is different, the indicator of mastering is not the same in different groups. For example, to take the educational process of the subject "Computer Graphics" in some groups, you have to organize the educational system based on simple concepts and rules, provide information to students of such groups about all the elementary orders of graphic programs that are the main meaning of the subject being studied. But let's take into account the fact that in many groups, students learn the subject very quickly, then in these groups. It is necessary to organize lessons based on the use of elements of the complex design process 
in graphic programs. Therefore, the implementation of the identification of students of these groups of interest in the subject, ability and initial knowledge using an automated questionnaire - a questionnaire gives a positive result $[12,13]$.

Determining students' interest in a subject and monitoring their knowledge in educational activities is considered one of the main stages of learning. Keeping this aspect in mind today, through the use of automated software systems, it is possible to achieve the introduction of automated knowledge assessment systems into the educational process. According to experts, the change in methods and forms of education is a characteristic aspect of information technology [14, 15].

This is the opinion of a well-known scientist in the field of education about the importance of quality control of the degree of knowledge: "All aspirations not based on practical reform of the system of testing the circle of knowledge, aimed only at improving the quality of education, as a rule, did not give the expected results."

Based on the analysis of the above opinions, the necessity of an innovative approach to the methodological organization of the stage of monitoring students' knowledge is substantiated. A number of studies were carried out in this direction. For example, the introduction of computer technologies in teaching graphic subjects, the methodological features of using the subject of computer graphics are scientifically substantiated in the works of D.F. Kuchkarova, T. Rikhsiboev, A.K. Khamragulov, Zh.Zh. Dzhanabaeva, N.Zh. Yodgorov, G.V. Vinogradova, K.R.Ovchinnikova, A.D.Botvinnikov, A.Ya.Blaus, A.S. Kamenev, I.E. Malakhotkina, etc. In the field of substantiating the design of the use of computer technologies in the learning process in universities were conducted by M.A. Faiziev, N.G. Shirokova, I.S. Chiruk, O.I. Belyakov, O. V. Lvova, N. N. Gomulina, S. V. Panyukova, S. Saidaliev, D. S. Saidakhmedova and others.

Although V.P. Bespalko, N.O. Verbitskaya, Yu.M. Zabrodin, N.V. Kuzmina, U.N. Nishonaliev, Ch.T. Shokirova conducted scientific research on the development of students' creative thinking in graphic subjects and increasing the effectiveness of learning based on program control; there has not been sufficient research to create a general automated system for determining the interest of students in the subject of computer graphics and control of their knowledge [16].

The development of students' creative thinking adapted to the environment, teaching general professional engineering subjects that are difficult to assimilate by students, based on an approach that ensures a sufficient approximation of the subject to their circle of thinking, not only ensures the effectiveness of education but is also very important in training competitive specialists and predicting their prospects.

\section{Methods}

Therefore, the introduction of computer technologies in the process of teaching graphic subjects, including "Computer Graphics" is considered an urgent problem associated with the following factors:

- effective organization of the educational process;

- increasing the activity of students in the learning process;

- development of students' spatial imagination;

- choice by the teacher of an effective method and approach to educational activities;

- introduction of an automated control system;

- development of students' creative thinking and creation of conditions for creative activities.

This means that tests of varying degrees of complexity in the discipline "Computer Graphics" for each type are compiled based on the following: 
1) theoretical questions related to the basic concepts of the discipline "Computer Graphics";

2) concepts and tasks related to the programs used (AutoCAD, CATIA, 3DMAX, ..., etc.), as well as tasks that provide one-step logical thinking of trainees, based on these drawings;

3) questions related to the execution algorithm and logical comprehension of practical tasks performed in graphic programs.

Considering the above, it can be noted that when compiling tests of varying degrees of complexity, it is necessary to adhere to the principle "from simple to complex". In tests of a certain degree of difficulty, the main place is given to the factors that must be formed in students. Their number determines the degree of difficulty of tests in the discipline "Computer Graphics". Below, these factors are given following tests of varying degrees of difficulty [17]. factors:

Students who have completed tests of the 1st degree of difficulty have the following

- theoretical knowledge;

- storage in memory. factors:

Students who have completed tests of the 2nd degree of difficulty have the following

- logical comprehension of a one-step task;

- correct implementation of the algorithm for solving the problem;

- the ability to apply in the process of solving problems;

- getting accurate results.

Students who completed tests of the 3rd degree of difficulty show the following factors:

- logical comprehension of the stages of solving problems;

- making the right decision;

- correct execution of the algorithm for taking measurements;

- use in solving similar problems;

- getting the right decision;

- the ability to analyze the results obtained.

These factors are interrelated, and they are used as a unit of measurement in assessing the degree of knowledge of students in the discipline "Computer Graphics". The more the student's knowledge of these factors corresponds, the more likely he will be able to complete tasks of a certain degree of complexity.

A scientist from Denmark G. Rush [5] introduced a new unit of measurement, "logit", which allows reflecting on the same scale the level of knowledge of the student and the degree of difficulty of the test [18].

The degree of knowledge of a particular student is determined by the number of points scored by him based on the test results.

$$
Q_{i}=\ln \left(p_{i} / q_{i}\right), i=1,2, \ldots n
$$

Here: $n$ is the number of subjects, $p_{i}$ is the proportion of possible correct answers to the number of tests; $q_{i}$ possible incorrect answers for the number of tests.

The complexity of the test items is determined by the same principle.

$$
\beta_{j}=\ln \left(p_{j} / q_{j}\right), j=1,2, \ldots n
$$


Here: $n$ is the number of test items, $p_{j}$ is the share of possible correct answers of all students; $q_{j}$ possible incorrect answers of all students.

In determining the complexity of tests in the "Computer graphics" discipline, the factors formed in the subjects play an important role, and, given the number of these factors, it is possible to assess the degree of complexity of this test. factors.

To complete the test of the 1 st degree of difficulty, the student must show at least $\geq 2$

To complete the test of the 2 nd degree of difficulty, the student must show at least $\geq 4$ factors.

To complete the test of the 3rd degree of difficulty, the student must show at least $\geq 6$ factors, etc. according to this principle, the degree of difficulty in tests of an even greater degree of difficulty is determined.

While we will assume that there are 3 degrees of difficulty, to solve tests of each degree of difficulty, students must have the above factors $F_{i}, F_{j}, F_{k}$, and we will denote this in general form as

$$
F_{s}=F_{i}, F_{j}, F_{k} \ldots . F_{m}
$$

Hence, based on G. Rush's research results, the degree of knowledge of each student is determined by the formula (1). Taking into account the peculiarities of tests in computer graphics, we can note that $p_{i}$ - given in formula (1) is the proportion of possible correct answers to the number of tests and $q_{i}-$ are possible incorrect answers to the number of tests, regardless of the degree of complexity of the tests being solved, shows the relationship between the level of knowledge of the student and factors required of the student. (4)

$$
\left\{\begin{array}{l}
p_{\mathrm{i}}>q_{i} \text { if a } F_{S}>0 \\
p_{i}\left\langle q_{i} \text { if a } F_{S}<0\right.
\end{array}\right.
$$

Since the way the student decided on the test shows how much the necessary factors are formed. If we designate these factors according to the degree of test complexity $F_{i}, F_{j}, F_{k}$ $\ldots . . F_{m}$, then we get the following equation (5).

$$
\alpha_{p}\left\{\begin{array}{l}
D_{t}^{1}=F_{i} \\
D_{t}^{2}=F_{j} \\
D_{t}^{3}=F_{k} \quad i \geq 1,2 ; j \geq 1,2,3,4 ; \quad k \geq 1,2,3,4,5,6 ; \mathrm{m}=\mathrm{i}, \mathrm{j}, \mathrm{k}, \ldots . . \mathrm{r}, \\
\cdots \cdots \cdots \\
. D_{t}^{n}=F_{m} \\
\quad \alpha_{p}=D_{t}^{1}, D_{t}^{2}, \ldots, D_{t}^{n}
\end{array}\right.
$$

Here $F_{i}, F_{j}, F_{k}, \ldots . . F_{m}$ are factors required from a student when solving a test of a certain degree of difficulty, and $i, j, k, . ., m$ is the number of factors. 
$D_{t}^{1}, D_{t}^{2}, D_{t}^{3}, \ldots . . D_{t}^{n}$ is the degree of difficulty of the test, $a_{p}$ - the degree of difficulty of the test. As can be seen from formula (3), to complete the test of the 1 st degree of difficulty, a student needs at least two of the above factors, etc.

Therefore, the greater the number of factors noted in the tests, the higher $p_{j}$ - the proportion of possible correct answers to the number of tests, and vice versa, the smaller the number of factors, the more $q_{j}$ - possible incorrect answers to the number of tests, from here we derive the following regularity.

$$
\left\{\begin{array}{l}
p_{j}>q_{j} \text { if a } F_{S}>0 \\
p_{j}<q_{j} \text { if a } F_{S}<0
\end{array}\right.
$$

Suppose we form the above calculations based on the formula (2) of G. Rush. In that case, we get that the degree of test complexity according to computer graphics is directly proportional to the number of $p_{j}$ - the share of possible correct answers to the number of tests, $q_{j}$ is to possible incorrect answers to the number of tests, $\alpha_{p}=D_{t}^{1}, D_{t}^{2}, \ldots, D_{t}^{n}$ of the degree of complexity test and, based on this, we form (2) the equation.

The formula for determining the degree of complexity of computer graphics tests:

$$
\beta_{j}=\alpha_{p}\left(\ln \left(p_{j} / q_{j}\right)\right), j=1,2, \ldots n
$$

Below are examples of tests on computer graphics of 3 degrees of difficulty:

As noted above, tests of the 1 st degree of complexity require students to have theoretical knowledge of general concepts in the discipline and choose the right solution. This means that the student can find the right solution based on theoretical knowledge.

For example: to draw a straight line in AutoCAD you need to select ...

A) Line with Lines in the Draw (Draft) panel;

B) Line in the Draw (Draft) panel;

C) Half-Line in the Draw (Draft) panel;

D) Arc in the Draw (Draft) panel.

When performing the test of the 2nd degree of difficulty, the student and the requirements set in the test of the 1st difficulty require a logical understanding of the test task, correctly execute the solution algorithm, and achieve the result.

For example: in the first picture, define a row in which

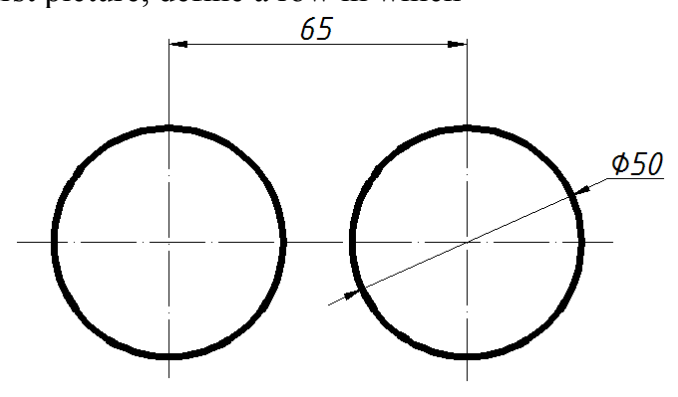

Fig. 1. Is the correct algorithm for conducting the external one specified? The radius of the circle is $50 \mathrm{~mm}$. 
A) "Circle" is selected - the right mouse button is pressed, and the KKR line is selected (tangent radius) - approximate points of the attempt are indicated - the radius of the circle $50 \mathrm{~mm}$ is entered - Enter is pressed once.

B) "Circle" is selected - the left mouse button is pressed, and the KKR line is selected (tangent radius) - approximate points of the attempt are indicated - the radius of the circle $50 \mathrm{~mm}$ is entered - Enter is pressed once.

C) "Circle" is selected - the button is pressed, and the KKR line is selected (casus radius) - the centers of the circles are indicated - the radius of the circle is entered $50 \mathrm{~mm}$ Enter is pressed once.

D) select "Arc" - indicate the approximate points of the attempt - enter the radius of the circle 50mm - press Enter once.

To complete the test of the 3rd degree of difficulty from the student, in addition to the knowledge and skills necessary for solving tests of the 1st and 2nd degree of difficulty, logical and creative comprehension of tasks with a step-by-step solution is required, the ability to make the right decision, get the result, analyze the received result.

For example: Determine the sequence of actions when positioning this axonometric image using the task "Divide" (Viewports).

A) Menu View - Viewports - New VP - Four: evenly

B) Menu Edit - Viewports - New VP - Four: Evenly

C) Draw menu - Viewports - New VP - Four: evenly

D) Menu View - 3D Views - New VP - Four: Evenly

In the implementation of the above factors, it is first necessary to determine students' interest in the subject of "Computer Graphics" using an automated "Questionnaire Questionnaire". In the "Questionnaire-questionnaire", the initial knowledge of students on the subject "Descriptive geometry and engineering graphics" is determined; with the help of assessing questions of interest and attitude to the subject, students are divided into categories. In order for students to perfectly master the subject of "Computer Graphics", they must have sufficient qualifications to work on graphic programs and carry out the design process based on the rules of the subject "Descriptive Geometry and Engineering Graphics". Therefore, initial knowledge of the subject "Descriptive geometry and engineering graphics" and interest in this subject for a perfect mastering of the subject "Computer graphics" are of great importance.

When comparing the categories, it is revealed that the R-category of students is able to think creatively, they can reach $86 \%-100 \%$ indicator. S-category students can think partially creatively, can reach $71 \%-85 \%$. The T-category of students, who have simple concepts in the subject, can reach $56 \%-70 \%$. The U-category has no simple concepts; it can be assumed that it can reach $55 \%$ of the subject mastery rate. $(1,2)$ the results of the "Questionnaire-questionnaire" are determined by the following formulas:

$$
n=\sum_{i=1}^{N} m_{i}, m_{i}>0
$$

Here $m_{i}$ is contains the correctness or incorrectness of the answer, $N$ - is the number of questions, $n$ is the sum of correct answers.

View in the percentage of answers to the questions of the "Questionnaire":

$$
F=\frac{n \cdot 100 \%}{N}
$$

$N$ is the number of questions, $n$ is the sum of correct answers.

After dividing all students into categories, based on the results obtained, the teacher determines the methodology for conducting classes; that is, the teacher must identify a pedagogical approach concerning a specific group. For example, suppose in some groups 
the results are higher than in other groups. In that case, the establishment of a complex process of designing the teacher's activities should be aimed at acquiring students' skills in conducting creative activities. In groups with lower indicators, the teacher needs to use auxiliary aids to develop students' spatial imagination and assimilation of graphic programs. To control students' knowledge obtained in the subjects, the automated program "Test" is used at a certain time of the educational process. This is an automated type of control of students' knowledge gained in educational activities.

Processing the test control results using a computer will ensure objectivity. Here all work is carried out based on a single software. To achieve an objective interpretation of the results, you need to have a common opinion on the assessments of several teachers. The processing of the results using a computer is objective, and precise organic relationships are determined.

K.G. Delikatny states: "Each examiner, along with the general criterion for assessing knowledge, has his own approach, his own understanding of the tendencies of pedagogical requirements and his own honesty, his attitude to the assessment."

Considering the above, the "Questionnaire" program was created, which is used in the educational process to control the interest in the subject "Computer graphics" of students and their knowledge. This program is a general automated system for determining students' interest in the subject and their knowledge; they are determined on the basis of the "Questionnaire" and "Test".

Each student's answer to the control of the test is automatically checked by the program and transferred to the results window. (3.4). The results of the test control of students are determined using the following formulas:

$$
n_{t}=\sum_{i=1}^{N_{t}} m_{i}, m_{i}>0
$$

Here $m_{i}$ is contains the correctness or incorrectness of the answer, $N_{t}$ is the number of questions, $n_{t}$ is the sum of the correct answers.

Percentage of response data:

$$
F_{t}=\frac{n \cdot 100 \%}{N}
$$

Using the above formulas, it is possible to determine the number of correct or incorrect students' answers to test questions. But, seeing in what questions students made mistakes, they can better prepare for these questions. To determine which questions they answered correctly and which ones incorrectly, the following program window is used. The requirement to use different variants of one test is selected using adaptive computer systems, based on the answers given by the student to the previous task. And now, it is possible to determine the range of changes in knowledge in the subject during the educational activity of each student by comparing the test results with the results of the questionnaire. (5) to implement it, we use the following formula:

$$
T=\left\{\begin{array}{l}
F-F_{t}, \quad F \geq F_{t} \\
F_{t}-F, \quad F_{t}>F
\end{array}\right.
$$

Here $F$ is the results of the "Questionnaire-questionnaire", $F_{t}$ is the results of the control "Test". Based on the above formula (5), we enter into the software system a window for comparing the results of the 1 st and 2 nd control. As a result, the following window appears.

\section{Results and Discussion}


Based on these results, the teacher can determine the range of changes in students' knowledge during the course of educational activities and draw conclusions about the positive or negative results of the method organized by him in the general group. Below are the groups that have passed the test experience based on the created program table 1.

Table 1. Passed test experience based on the created program

\begin{tabular}{|c|c|c|c|c|c|c|}
\hline 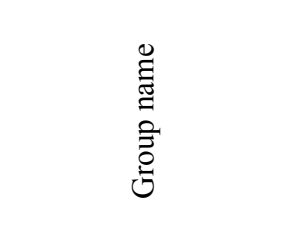 & $\begin{array}{l}\text { 苛 } \\
\frac{0}{0} \\
\text { : }\end{array}$ & 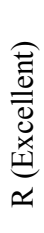 & $\begin{array}{l}\text { } \\
\text { is } \\
0 \\
0\end{array}$ & 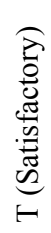 & 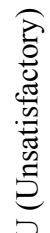 & 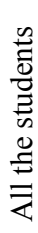 \\
\hline \multirow{2}{*}{$\begin{array}{l}\text { 1-experimental group } \\
\text { 2-experimental group }\end{array}$} & \multirow{2}{*}{$\begin{array}{l}\text { Profiles-poll } \\
\text { results }\end{array}$} & 7 & 11 & 8 & 7 & 33 \\
\hline & & 6 & 16 & 4 & 4 & 30 \\
\hline \multirow{2}{*}{$\begin{array}{l}\text { 1-experimental group } \\
\text { 2-experimental group }\end{array}$} & \multirow{2}{*}{ Test results } & 1 & 3 & 11 & 18 & 33 \\
\hline & & 2 & 5 & 12 & 11 & 30 \\
\hline
\end{tabular}

As you can see from the above table, the results of the Questionnaire-questionnaire belong to the highest category R (Excellent) and S (Good), and the Test results are lower. The indicators of students belonging to the category $\mathrm{T}$ (Satisfactory) and U (Unsatisfactory) according to the test results occupy positions relatively higher than figure 2 .

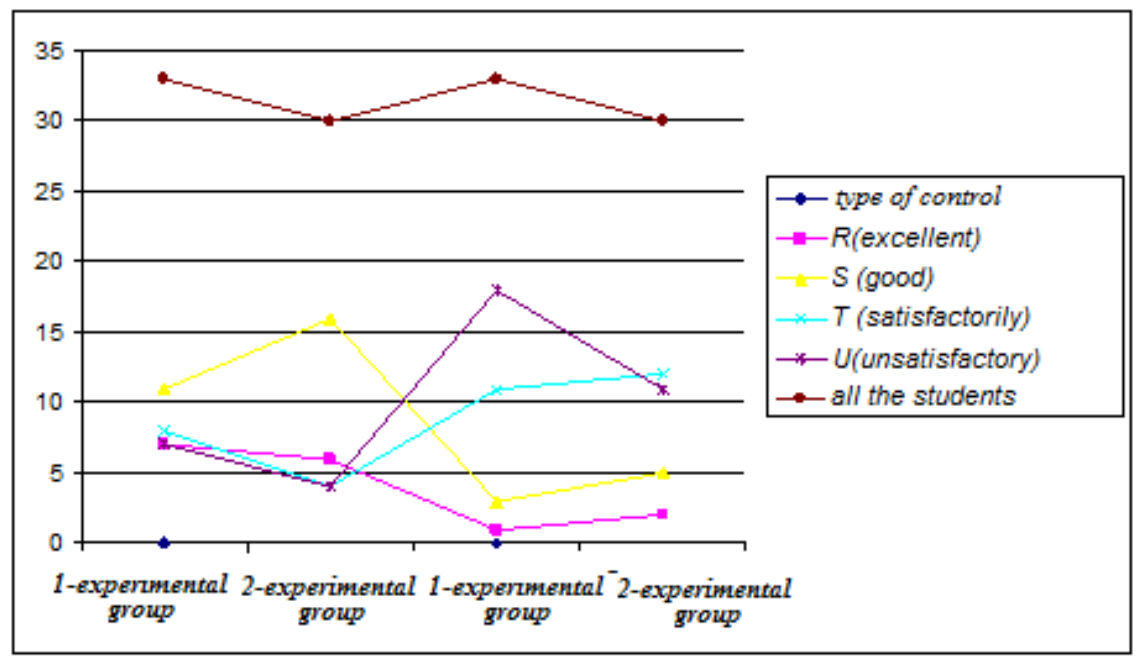

Fig. 2. Comparative chart of experimental groups

Considering all this, an automated software system for determining interests, abilities and initial knowledge in the educational process was created, that is, the software "Questionnaire". The software consists of two parts: "Questionnaire-teacher" and "Questionnaire-student". The automated software system is designed to work in the network; the "Questionnaire-teacher" program is loaded into the server. The "Student Questionnaire" program is installed on other computers in the network. After installing the "Questionnaire-teacher" program, he finds all computers with installed programs "Questionnaire-student" and establishes a connection with them. The relationship between 
the programs "Questionnaire-teacher" and "Questionnaire-student" is displayed in the following form figure 2 .

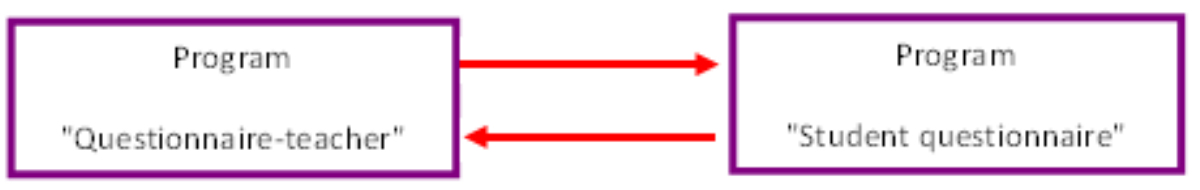

Fig 3. Relationship between the "Questionnaire-teacher" and "Questionnaire-student" programs

All data is stored in the "Questionnaire-teacher" program and transferred to the "Questionnaire-student" program. This software can be used to monitor the interests, abilities and knowledge of students as a test "Test" and "Questionnaire". In the questionnaire-questionnaire conducted on the subject, the interests, abilities and knowledge of the chairmen are divided into 4 types using the questions asked on the subject. 1) R-high degree, that is, he knows how to think creatively; S - a good degree, then esit can partially think creatively; $\mathrm{T}$ - satisfactory degree, has simple concepts on the subject; Uunsatisfactory degree, does not have simple concepts on the subject [19,20].

This questionnaire-questionnaire is carried out at the beginning of the educational process, and the interest of students in the subject "Computer Graphics" and initial knowledge is determined. To conduct the automated program "Questionnaire" for the experiments, 3 groups with an equal number of students were selected, and experiments were carried out on the subject of automated software "Computer Graphics" based on the "Questionnaire-questionnaire". According to the results of this experience, categories were identified that determine the degree of interest in the subject of "Computer Graphics", abilities and initial knowledge of students and are shown in the table below table 2 .

Table 2. . "Computer graphics", abilities and initial knowledge of students and shown

\begin{tabular}{|c|c|c|c|c|c|c|}
\hline № & Group name & $\mathrm{R}$ & $\mathrm{S}$ & $\mathrm{T}$ & $\mathrm{U}$ & $\begin{array}{c}\text { Total number of } \\
\text { students }\end{array}$ \\
\hline 1 & 205- SXMIM-12 & 6 & 12 & 6 & 1 & 25 \\
\hline 2 & 206- SXMIM-12 & 3 & 9 & 8 & 6 & 25 \\
\hline 3 & 207 - SXMIM-12 & 3 & 8 & 11 & 2 & 25 \\
\hline
\end{tabular}

Based on the data given in the table1 Group 1 has a high degree of academic performance, interest in the subject, the ability in them is high, and the group is considered to have more opportunities in an atmosphere of creative thinking. In the 2nd and 3rd groups, the indicator of the R-category is the same. Still, as we see in the other groups, the indicators of results show $\mathrm{S} 2<\mathrm{S} 3 \mathrm{~T} 2<\mathrm{T} 3$ and $\mathrm{U} 2>\mathrm{U} 3$, these signs, as mentioned above, are a kind of indicators of the categories $\mathrm{S} 2<\mathrm{S} 3 \mathrm{~T} 2<\mathrm{T} 3$ and $\mathrm{U} 2>\mathrm{U} 3$. These results show that the performance of group 3 is higher compared to group 2, but if you pay attention to $\mathrm{S} 2<\mathrm{S} 3$, you can see that the number of students with a good level in group 2 is greater than in group 3. And this means that in group 2, the number of students who have the opportunity to achieve good academic performance may increase. These results enable the teacher to predict the degree of mastery of the subject by the students. Figure 3 shows a comparative diagram of the results of the experiments carried out in three groups. The results of the experiments show that conducting an automated "Questionnaire questionnaire" at the beginning of the educational process helps in determining the attitude and interests to the subject, their abilities and initial knowledge figure 4. 


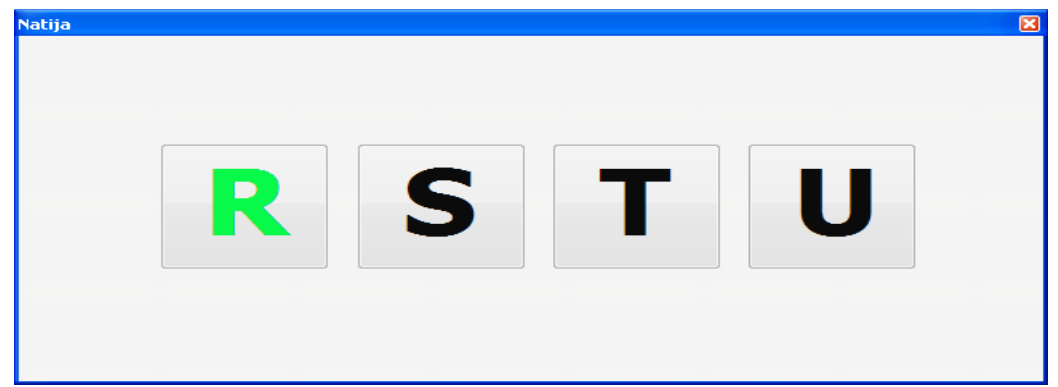

Fig. 4. Test result software

In the control of students 'knowledge, the indicators of students' mastery of the subject and the efficiency of the learning process are visible as a result of the use of computer software systems in the learning process. The advantage of this program is that the results achieved by students are divided into time, date and category and stored in tabular form in the results window of the program. The teacher can also get these results in the form of a list of directions and groups. Another feature of the program is that it creates a universal form of control. Because, using this program, it is possible to perform both a questionnaire and a test on the subject. Depending on the answers to the question entered, the program can change the number of answers. Therefore, using this program can be used in the organization of questionnaires and tests on optional subjects.

By applying such computer software systems in the educational process, processing the obtained results, using them in practice and analyzing their results, it is possible to quickly automatically analyze the theoretical and practical knowledge of many students in the subject. Based on these results, the teacher can determine the range of change of knowledge of each student during the learning activity and conclude whether the teaching method he/she organized in the general group gave a positive or negative result.

Figure 4 shows a comparative diagram of the results of the experiments carried out in three groups. The results of the experiments show that conducting an automated "Questionnaire - questionnaire" at the beginning of the educational process helps in determining the attitude and interests of the subject, their abilities and initial knowledge.

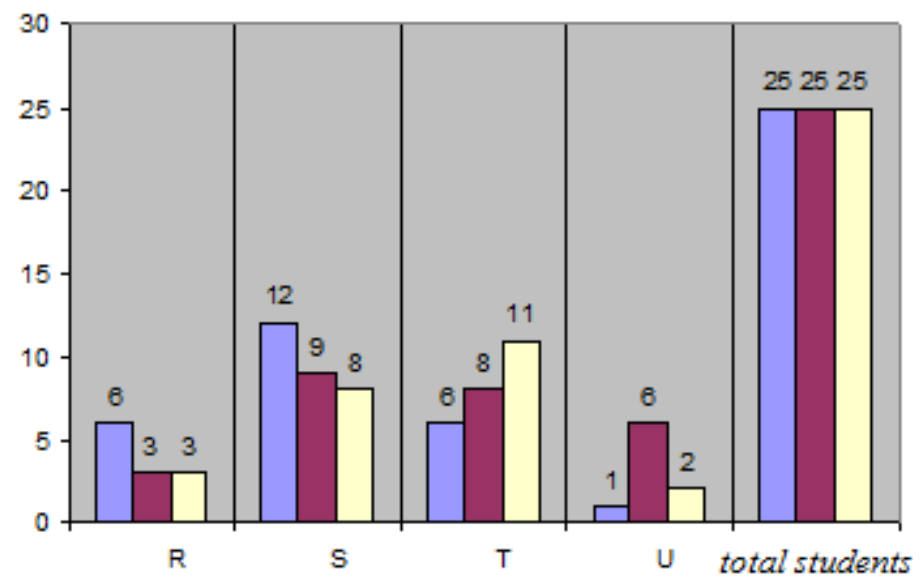

ㄴ 205. SХMИM-12 2 206. SХMИM-12 व3 207- SХMИM-12

Fig. 5. Comparison chart of 3 experimental groups 
In the educational process, through the use of a questionnaire, you need to pay attention to the following:

- the composition of the questions of the questionnaire focus on determining interests, abilities and initial knowledge;

- analysis of the results of the groups in which the questionnaires were conducted;

- the teacher's definition of the organization of the educational process based on these results.

The above factors are considered necessary to increase the efficiency of the educational process and serve as the foundation for the education system when introducing an automated assessment system.

\section{Conclusions}

Therefore, it is necessary to develop the spatial imagination of the student and create their skills in working with graphic programs, which is the main problem in the educational process of the subject "Computer Graphics".

To implement it in the learning process, you need to use the following:

- to determine students' interest and ability in the subject using automated software systems;

- to determine the educational methodology in certain groups, based on the results obtained (for example, the results of the "questionnaire-questionnaire" of the students of the group);

- development of theoretical and practical topics based on 2D and 3D modelling;

- development of software-pedagogical tools based on 2D VA 3D modelling and introduce it into the educational process;

- when mastering graphic programs, use the methods of performing graphic tasks of the curriculum on a computer;

- establish automated multivariate test control;

- organize independent education.

Instead of a conclusion, we can say that computer technologies at different stages of graphic education, while helping future specialists become excellent experts in their field, also provide them with modern knowledge and skills.

So, when drawing up tests of varying degrees of complexity in the discipline "Computer Graphics", the main role is played by the requirements for the knowledge and skills of trainees and the compliance of trainees with these requirements. This is regarded as the above factors. In conclusion, it can be noted that the use of tests of varying degrees of complexity for an objective assessment and the development of knowledge and skills of trainees will bring positive results and raise the effectiveness of training to a new level.

\section{References}

1. Qosimov J., Nasritdinova U., Nigmanov R., Urishev A., Edilboyev U. Selection of software for modeling developments and technologies, International Journal of Advanced Science and Technology, pp.554-558, (2019)

2. Qosimov J., Nasritdinova U., Nigmanov R., Edilboyev U. Three dimensional modeling technology for computer science education, XII International Scientific conference on Agricultural Machenery Industry, pp.145-151, (2019)

3. Abdullayev Z., Nasritdinova U. Effectiveness of virtual simulation of three dimensional Objects in the Devolopment of culture and professional Skills of the audience of the project, International conference on information Science and 
communications technologies: Applications, trends and Opportunities ICIST 2019, pp. 455-460, (2019)

4. Smit Y., Farberman B., Objective assessment of students' knowledge. Tutorial, p. 114, Tashkent (2008)

5. Rasch G. Probabilistic model for some intelligence and attainment tests, Chicago, Univ. of Chicago Press. p. 199, (2010)

6. Little, A. Education and employment: the evolution of concepts. Plans for the Future: UNESCO Education Challenges, № 1, (1987)

7. Delicate K.G. Methodical recommendations for teachers conducting entrance exams to the University. p. 38, Kiev, KSU, (2005)

8. Nasritdinova U.A. The program "Questionnaire" used in the learning process. "Certificate of official registration of the created program for electronic computers" No. DGU-02772 RA № 5, pp. 289-2906 (2013)

9. Thomas K., Davis J., Openshaw D. and J. Bird. Prospects for programmed learning. Per. from English, p. 246, (2010)

10. Sidorenko E.V. Methods of mathematical data processing in psychology, p. 320, St. Petersburg, (2007)

11. Spearman C.E., "General intelligence" objectively determined and measured. Amerikan Journal of Psychology, 5, p. 201-293, (2008)

12. Hoi Suen, Methodological Analysis of Pedagogical Measurement Theories, University of Pennsylvania USA, (2004).

13. Nasritdinova U., Khaqberdiyev B. Results theoretical study of the form ofa front surface of a chisel-cultivator stand, "International Scientific Conference construction Mechanics, Hydraulics and Water Resources Engineering"., pp. 454-463, (2019)

14. Qosimov J., Nasritdinova U., Nasritdinov A. "Dynamic and kinematic conditions for designing water channels", VII International Scientific Conference integration, partnership\& innovation in construction science and education, pp.333-345, (2020)

15. Abdullayev Z., Nasritdinova U., Kamalova Sh. Modeling dynamic operation of mechanisms in Autodesk Inventor Professional 11, International conference on information Science and communications technologies: Applications, trends and Opportunities ICIST 2019, pp. 352-357, (2019)

16. Nasritdinova U.A., Khaqberdiyev B. Results theoretical study of the form ofa front surface of a chisel-cultivator stand, For tacing part in the International Scientific Conference "Construction Mechanics, Hydroulics and Water Resources Engineering, pp. 100-106, (2020)

17. Abdullaev Z., Nasritdinova U., Xamraeva Sh. Use of interactive methods in distance learning, Internauka nauchniy zhurnal, pp. 35-40, Moskva, (2019)

18. Nasritdtnova U.A. The use of optimal methods of mathematical statistical analysis in assessing the results of a pedagogical experiment. Lecturer of the XXI century Scientific journal of Moscow State University 2017 № 222-227, (2017)

19. Nasritdinova U.A. Modern problems and solutions of methods of teaching computer graphics, Publishing House, p. 172, (2015)

20. Nasritdinova U.A. The use of optimal methods of mathematical statistical analysis in assessing the results of a pedagogical experiment, Teacher XXI century, Moscow, 2017. № 1. - S. 222-227, (2017)

21. Nasritdinova U.A. The effectiveness of the organization of practical classes in computer graphics using video lessons, Pedagogical education, № 4, pp. 53-58, Tashkent, (2014) 